\title{
Cultural Additivity: A Mapping with Essentialism, Creolization, Hybridity, and Syncretism
}

\author{
Minh Hoang Nguyen \\ Hong Kong Nguyen \\ Manh Tung Ho \\ Manh Toan Ho
}

Centre for Interdisciplinary Social Research

Phenikaa University

Yen Nghia, Ha Dong District, Hanoi 100803, Vietnam

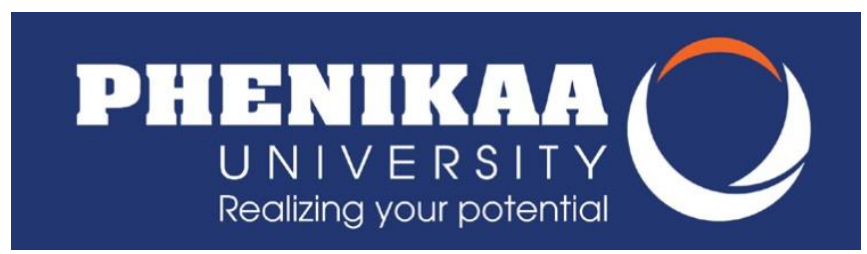

January 15,2021

"Cultural Additivity" is the concept proposed by Vuong et al. to demonstrate the interactions of various cultural values in a society [1]. However, there have been multiple concepts discussing the interaction between different cultural values, such as Hybridization/Hybridity, Creolization, Syncretism, etc. So, how can we distinguish cultural additivity from other concepts, which may sound similar?

In this essay, we propose a diagram for doing such a task (see Figure 1). 


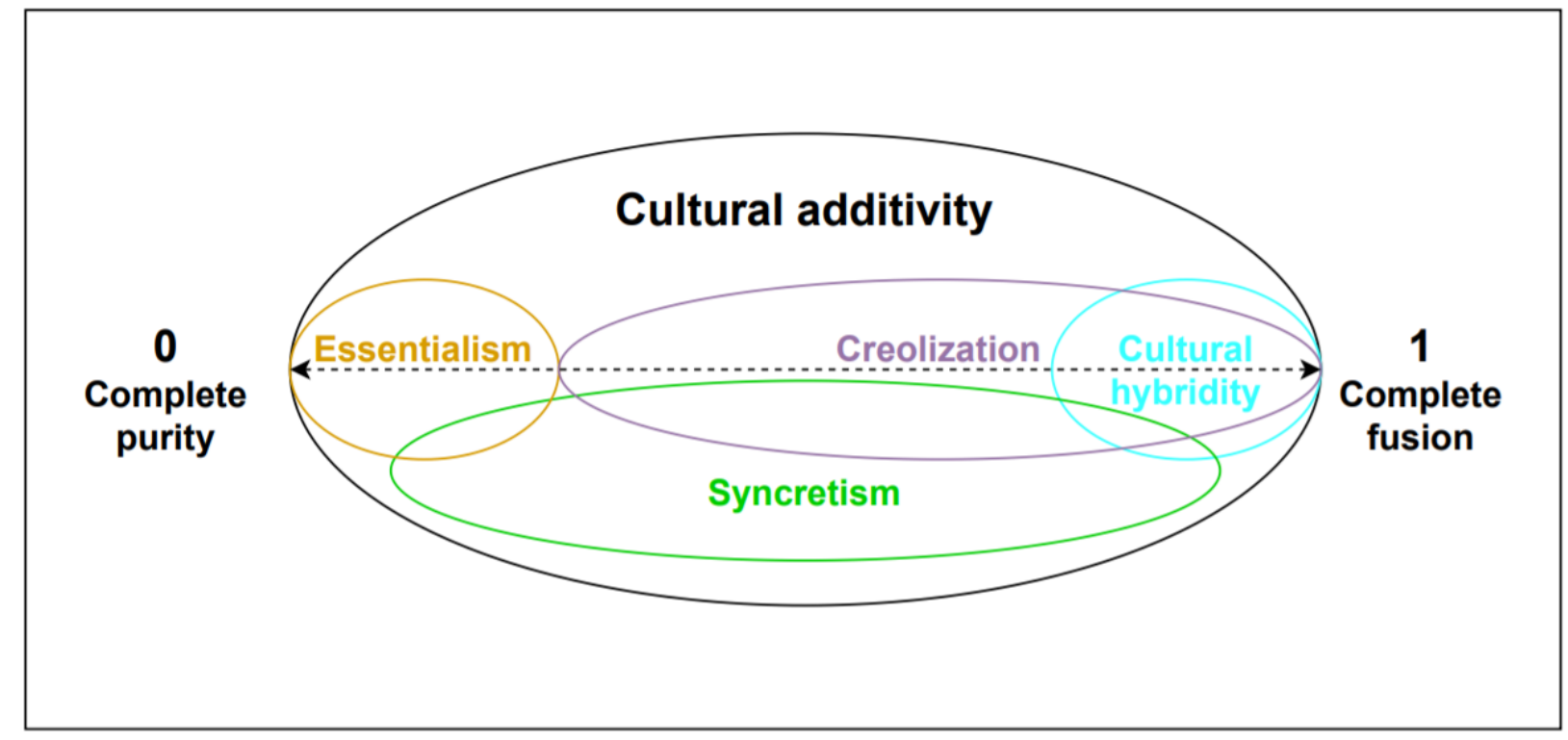

Figure 1: The mapping of Cultural Additivity.

First of all, we assume that cultural additivity is a set of interactions between various cultures, of which the additivity degree is a continuum ranging from 0 to 1 . When the cultural additivity level equals zero, the culture (or set of core values) in a society is unique and has total suppression over emergent values; we call it "no additivity" (or "complete purity").

Thus, the sub-set of Essentialism, which advocates the view that a group of people suppress, homogenize, and fix dissimilarities for reserving a so-called "identity" [2], takes the closest place to point zero.

In contrast, the farthest right, which we denote as one, indicates the stage of "complex additivity" (or "complete infusion"). Because the sub-set of Hybridity (or Cultural Hybridity) represents a stage of high fusion level of different cultural values [3], we position it nearest to the "complete fusion" point. The sub-set of Creolization, demonstrating the acquisition, convergence, acclimation, indigenization, and transformation of various cultural values in a society [4], is also placed closest to the "complete fusion" point. However, the sub-set does not overlap with the sub-set of Essentialism because the acquisition, convergence, acclimation, indigenization, and transformation cannot happen if the host culture's values suppress and eliminate new cultures.

Finally, the most similar concept with Cultural Additivity is Syncretism, which reflects the interactions between indigenous religions and a missionary religion, so we consider the sub-set of Syncretism to overlap with all three other sub-sets $[4,5]$. Nevertheless, Syncretism has only been applied within the religious discourse, so it is plausible to put Syncretism as a sub-set of the set of Cultural Additivity. 
Despite incompleteness and weaknesses, the mapping is one of the first endeavors to position Cultural Additivity within the tremendous volume of cultural studies' literature. Through positioning the concept, we expect it to be a useful tool, along with the Mindsponge mechanism [6,7], for interpreting and explaining economic, environmental, and social issues [8-16]. Therefore, we welcome all colleagues' comments to make the concepts more precise, solid, and easier to be operationalized.

\section{References}

[1] Quan-Hoang Vuong, et al. (2018). Cultural additivity: behavioural insights from the interaction of Confucianism, Buddhism and Taoism in folktales. Palgrave Communications, 4(1), 143.

[2] Andrew Sayer. (1997). Essentialism, Social Constructionism, and beyond. The Sociological Review, 45(3), 453-487.

[3] Andreas Ackermann. (2011). Cultural hybridity: between metaphor and empiricism. In: Philipp Wolfgang Stockhammer (ed) Conceptualizing cultural hybridization: a transdisciplinary approach. Springer: Berlin, Heidelberg, pp. 5-25.

[4] Charles Stewart. (2011). Creolization, hybridity, syncretism, mixture. Portuguese Studies, 27(1), 48-55.

[5] Helmer Ringgren. (1969). The problems of Syncretism. Scripta Instituti Donneriani Aboensis, 3, 7-14.

[6] Quan-Hoang Vuong. (2016). Global mindset as the integration of emerging sociocultural values through mindsponge processes: A transition economy perspective. In J. Kuada (Ed.), Global Mindsets: Exploration and Perspectives (pp. 109-126). London: Routledge.

[7] Quan-Hoang Vuong \& Nancy K. Napier. (2015). Acculturation and global mindsponge: an emerging market perspective. International Journal of Intercultural Relations, 49, 354-367.

[8] Quan-Hoang Vuong, et al. (2020). On how religions could accidentally incite lies and violence: folktales as a cultural transmitter. Palgrave Communications, 6(1), 82.

[9] Quan-Hoang Vuong. (2021). The semiconducting principle of monetary and environmental values exchange. Economics and Business Letters, 10(3): article in press.

[10] Phạm Minh Chính, Vương Quân Hoàng. (2009). Kinh tế Việt Nam: Thăng trầm và đột phá. Nxb Chính trị Quốc gia, Hà Nội.

[11] Phạm Minh Chính, Vương Quân Hoàng. (2008). Bối cảnh tài chính Việt Nam 19971998 và 2007-2008: Khoảng cách và biến đối. Nghiên cứu Kinh tế, 48(7), 3-24. 
[12] Viet-Phuong La, et al. (2020). Policy response, social media and science journalism for the sustainability of the public health system amid the COVID-19 outbreak: The Vietnam lessons. Sustainability, 12(7), 2931.

[13] Quan-Hoang Vuong. (2020). Reform retractions to make them more transparent. Nature, 582, 149.

[14] Quan-Hoang Vuong, Manh-Tung Ho, Hong-Kong T. Nguyen, Minh-Hoang Nguyen. (2019). The trilemma of sustainable industrial growth: Evidence from a piloting OECD's Green city. Palgrave Communications, 5(1), 1-14.

[15] Minh-Hoang Nguyen, Thanh-Hang Pham, Manh-Toan Ho, Huyen Thanh Thanh Nguyen, Quan-Hoang Vuong. (2021). On the social and conceptual structure of the 50-year research landscape in entrepreneurial finance. SN Business \& Economics, 1(2), 1-29.

[16] Minh-Hoang Nguyen, Quan-Hoang Vuong. (2021). Evaluation of the Aichi Biodiversity Targets: The international collaboration trilemma in interdisciplinary research. OSF Preprints. DOI: 10.31219/osf.io/84j76 